\title{
Training Computational Thinking through board games: The case of Crabs \& Turtles
}

\author{
Katerina Tsarava ${ }^{1}$, Korbinian Moeller ${ }^{1,2,3}$, Manuel Ninaus ${ }^{1,3}$ \\ ${ }^{1}$ Leibniz Institut für Wissensmedien, Tübingen, Germany \\ \{k.tsarava, k.moeller, m.ninaus\}@iwm-tuebingen.de \\ ${ }^{2}$ Department of Psychology, Eberhard-Karls University, Tübingen, Germany \\ ${ }^{3}$ LEAD Graduate School \& Research Network, Eberhard-Karls University, Tübingen, \\ Germany
}

\begin{abstract}
As a cognitive ability computational thinking describes a specific way of algorithmic reasoning building on concepts and processes derived from computer programming/coding. Recently, computational thinking was argued to be a fundamental and educationally relevant 21st century skill that should be fostered already in childhood. Accordingly, we developed three life-size board games - Crabs \& Turtles: A Series of Computational Adventures - aimed at providing an unplugged and low-threshold introduction to computational thinking. In particular, the games aimed at introducing basic coding concepts and computational thinking processes to 8 to 9-year-old primary school children. In the current study, we first describe the design of the games in detail to explicate the development process and allow for reproducibility. We then report on a first empirical evaluation of feasibility and user experience of our educational board games in a twophase approach. We conducted quantitative analyses of player experience and qualitative feedback of adult student participants (Phase 1) and a sample of gamification experts and teachers (Phase 2). We examined users' game experience with an adult population to ensure the game's appropriateness. Results indicated overall positive game experience for all three games. Future studies would be desirable, which should evaluate player experience and learning outcomes in the primary target population of children.
\end{abstract}

Keywords: educational board games, computational thinking, coding, embodied cognition;

\section{Introduction}

Computational Thinking (CT) denotes the idea of developing a generic solution to a problem by decomposing it, identifying relevant variables and patterns, and deriving an algorithmic solution procedure [1]. As such, CT represents a cognitive ability to apply fundamental concepts and reasoning that derive from computer science in general and computer programming/coding in particular to different other domains, including real life activities [2]. Accordingly, CT is considered to be a fundamental ability for everyone and not just for computer scientists [1]. The psychological construct of CT as a cognitive ability shares common concepts with coding as a practical skill. Central concepts in coding are the generic ideas of sequencing, loops, parallelism, events, conditionals, operators, and data/variables [3]. Correspondingly, CT abilities specifically draw on 
processes such as algorithmic thinking, conditional logic, decomposition, abstraction, pattern matching, parallelization, evaluation, and generalization [4][5]; thereby reflecting cognitive instantiations of concepts central to coding.

Importantly, these concepts as well as their cognitive counterparts in CT are not to be understood as domain-specific in the sense that they can only be applied to the domain of computer science. Instead, CT should be viewed as a more general problem solving strategy, which can be applied to different domains over and beyond computer science. Therefore, CT has been suggested to be a fundamental cognitive ability that should be acquired in education - comparable to literacy and numeracy [6].

This broad applicability of CT abilities has lately led to several adaptations and reformations of educational programs (e.g., in Finland where coding was introduced as a subject recently [7]; [8]). Governments and educational institutions all over the world have been working on a coherent definition of CT and its integration in curricula of educational programs of primary, secondary, and higher education (e.g., [9-12]). This envisaged societal relevance of CT and its wide range of applicability inspired us to develop a training of practical coding skills integrated into a course on CT applied to various STEM contexts for 3rd and 4th graders (for the overall course program see [13]). This approach aims at highlighting the relevance of coding concepts and CT not only for digital contexts, but also real-life problems in general and STEM contexts in particular, thereby increasing students interest in improving their CT skills. Moreover, taking into consideration common concerns on introducing coding already in primary school [14], we aimed at implementing a game-based approach of learning by doing, focusing on central concepts of CT and not on practical coding skills related to specific programming languages. To do so, we developed and employed, among others, unplugged life-size board games Crabs \& Turtles: A Series of Computational Adventures (henceforth referred to as Crabs \& Turtles). A first empirical evaluation of these will be described in the current article. Games or game-based applications are an increasingly important approach in cognitive training, learning, and educational interventions because of their ability to keep learners motivated to play and to interact with the application or learning environment, respectively [15][16]. Recent research even indicated that game-based learning may be more effective in terms of learning and retention than conventional instruction methods [17].

Our game design relied on Piaget's theory of constructivism [18] and was further inspired by Papert's integrated constructionism approach [18][19]. In addition, we were inspired by the successful implementation of the haptic Logo-Turtle [18][20], which led to Logo visual programming language. As regards content, we considered the central concepts of coding as identified by [3]. After years of development and evaluation using the educational software Scratch, they identified seven overarching computational concepts, applicable to other programming and non-programming contexts but also generalizing beyond them: (i) Sequences, (ii) Loops, (iii) Parallelism, (iv) Events, (v) Conditionals, (vi) Operators, and (vii) Data. We integrated 6 of those concepts into our game content design and aimed at training children through un-plugged playing activities in a board game (Table 1). Here, we describe the development, design, and results of initial user tests of three games - all addressing different CT concepts - which are subsumed under the game series Crabs \& Turtles.

While there are a number of games aiming at training CT related abilities, most of them digital (e.g., Program your Robot [21]), only a few allow for non-digital haptic (e.g., Robot Turtles [22], Ricochet Robots [23], Pandemic [24]), and thus embodied or blended approaches (e.g., Osmo [25]). Moreover, these games can be further distinguished on whether they are commercial (e.g., Qwirkle [26]) or research and experimental project productions (e.g., Dragon Architect [27], Rabbit Escape [28]). All of them differ in their target audience, holistic perspective, and mode. Program your Robot for example is a web-based environment aiming at introducing computer programming concepts and various CT skills, such as problem solving, algorithm building, debugging, etc. In the game, players have to manipulate non-verbal commands by dragging and dropping them 
to program their robot to collect or avoid items. Dragon Architect is another web-browser game based on the Blockly [29] programming environment. It introduces concepts through puzzles that require a command solution which gradually becomes more difficult. There are quite a few games like those aiming at supporting CT skills with promising results so far [30][31]. However most of them lack qualitative and/or quantitative evaluation of their training effects.

Crabs \& Turtles shares common ideas with concepts of the educational Logo-Turtle and logo-inspired games and gamified educational activities. Importantly, the development process of the game was driven by own previous research and piloting. For instance, in 2016 we created a life-size board game called Turtle Steps [32], which can be considered the initial archetype educational intervention of Crabs \& Turtles. The game aimed at an embodied training of simple computational concepts with direct transferability to an educational Python editor environment, in which children were able to program in a native translation (Greek) of the actual Python programming language. After multiple pilot sessions with Turtle Steps, we derived conceptual ideas for the first game-based learning activities of Crabs \& Turtles. Note that we intentionally designed Crabs \& Turtles to be independent of any specific programming environment or language. The games' main target group is primary and secondary school students (8-12 years old) with no prior programming knowledge. It is, however, also suitable for older students and adults with no programming experience. The life-size dimensions of the game allow playability within the classroom or open-air spaces, such as a school yard. We chose the life-size game design to encourage active engagement and participation and thus to increase children's motivation for active learning (see [33] for an overview), on the one hand, and to enhance learning outcomes by an embodied experience of basic coding concepts and CT processes (cf. [34] for the concept of embodied cognition) supporting conceptual abstractions [35], on the other hand. The chosen un-plugged mode takes into account common concerns on introducing coding to primary school children (e.g. [36][37]) and offers a smooth and children friendly transition to digital more complex educational programming environments. Moreover, we feel that using a nondigital mode is crucial because it fosters the experience that possible applications of coding concepts and CT processes are not restricted to digital contexts but also generalize to real-life conditions [13]. Although the game can be used as a standalone game intervention, it is intended to be part of a structured course curriculum [13] which builds upon skills acquired within the game. To build our game we followed an iterative usercentered development process [38]. In particular, first design ideas of the game content were tested with a custom-made life-size game as a pilot educational intervention with primary school children [32]. Next, an early prototype was developed and tested in terms of usability of the materials needed to play the game (e.g., printed wooden floor tiles vs. linoleum canvas). During a 2 hour workshop with children, qualitative feedback was gathered and used to further improve the overall design. Finally, we examined users' game experience quantitatively with an adult population to ensure the game's appropriateness. After providing a detailed description of Crabs \& Turtles, the presented article reports the results of two evaluation studies with adults. Game experience was evaluated in two phases of playtesting with (i) a general audience of postgraduate students and went on to (ii) a more specialized group of gamification experts and teachers. In the following, we will first describe the design of the latest version of the game before reporting the results of the user experience studies afterwards.

\section{Game description}

Crabs \& Turtles consists of three different games: i. The Treasure Hunt, ii. The Race, and iii. Patterns. Currently, all three games are available in English, German ("Schildkröten

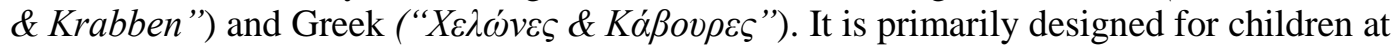


pag. 28

primary school level. The teachers or educators play an important role in each of these games and are in close contact with their pupils by acting as game masters. The games aim at training cognitive processes related to CT, such as algorithmic thinking, abstraction, pattern recognition, and decomposition (see Table 1). These processes can be either applied to specific coding skills (i.e., sequences, loops, conditionals, patterns, and events) or to mathematical skills (i.e, dealing with angular degrees in spatial orientation, addition, and multiplication) as well as skills relevant to both coding and mathematics (i.e., operators, variables, and constants). Our game design can be described within the framework for educational game design as proposed by [39]. The game design elements of goals, game mechanics and challenges were carefully selected and adapted when necessary, as was the element of feedback for each game decision given by a teacher serving as the game master in all three games. Moreover, elements and design decisions related to educational games like curriculum, readiness for learning, stimuli and rewards were cautiously selected.

Below we describe the game design of the three different games in detail and specify which cognitive processes and learning objectives, respectively, are primarily addressed in each of them.

Table 1. Coding skills \& CT processes as aimed game trained skills

\begin{tabular}{|c|c|c|c|c|c|c|c|c|c|c|c|}
\hline & \multicolumn{6}{|c|}{ Coding Concepts } & \multicolumn{5}{|c|}{ CT Processes } \\
\hline & $\begin{array}{l}\mathscr{U} \\
\stackrel{\bar{\Xi}}{0} \\
\bar{\Xi} \\
\tilde{E}\end{array}$ & $\begin{array}{l}0 \\
\tilde{0} \\
\tilde{\pi} \\
\tilde{\sigma} \\
\tilde{\sigma}\end{array}$ & 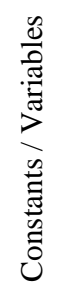 & 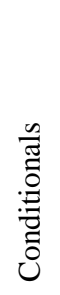 & $\begin{array}{l}\stackrel{0}{0} \\
\sum_{\vec{I}}^{0}\end{array}$ & 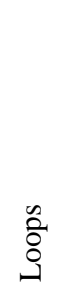 & 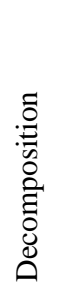 & 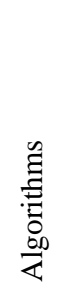 & 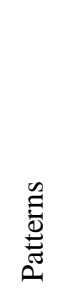 & 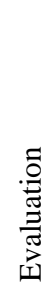 & 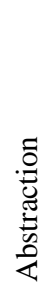 \\
\hline The Treasure Hunt & $\mathrm{x}$ & & & & & $\mathrm{x}$ & $\mathrm{x}$ & $\mathrm{x}$ & & $\mathrm{x}$ & \\
\hline The Race & & $\mathrm{x}$ & $\mathrm{x}$ & $\mathrm{x}$ & $\mathrm{x}$ & & & & & & $\mathrm{x}$ \\
\hline Patterns & & & & $\mathrm{x}$ & & & & & $\mathrm{x}$ & & \\
\hline
\end{tabular}

\subsection{The Treasure Hunt}

The Treasure Hunt is the first game of Crabs \& Turtles. In this game, users have to manipulate coloured game pieces representing turtles and crabs to figure out the most efficient way to collect treasures placed on the grid squares of the game board (see Figure 1). To move a crab or turtle users need to create effective sequences of commands on a sequence board (see Figure $1 \& 3$ ), which represent specific coding concepts. For instance, users have to build sequences of steps, turns and loops to move their game piece towards treasures fast and efficiently. As such, coding concepts and to a lesser degree mathematic abilities trained by this game are sequence building, value understanding, dealing with angular degrees and spatial orientation, loop creation, as well as conditional decisions.

Importantly, there are some restrictions with regard to game board and game pieces (turtle vs. crab) that affect the players' strategy. For instance, turtles can move only on grid squares indicating stone and grass grounds, whereas crabs can only move on grid squares representing stone and water ground (see Figure 2). Additionally, turtles can move only forward and backward, contrary to crabs that can move only sideways to either the left or right. However under specific conditions, for instance when an Event card from the pile, indicating Walk forward/backward, is picked up from a crab team, it can be used 
as it would be used by a turtle. Those cards are considered bonus cards for crabs and correspondingly Walk left/right are bonus cards for turtles because they allow movement in more directions than usual.

\subsubsection{Learning Objectives}

The main learning objectives of this game are the general introduction to algorithmic thinking, the use of commands in specific and sequential order, and the consideration of restrictions by possible conditions when forming a strategic solution to a problem. After playing the game we expect users to have acquired an understanding of what simple algorithms are and how they are formed as sequences of several commands that serve a specific strategical purpose. Besides that, we expect participants to be able to consider specific restrictions when making their decisions and recognize small repeatable patterns that can be folded into a loop.

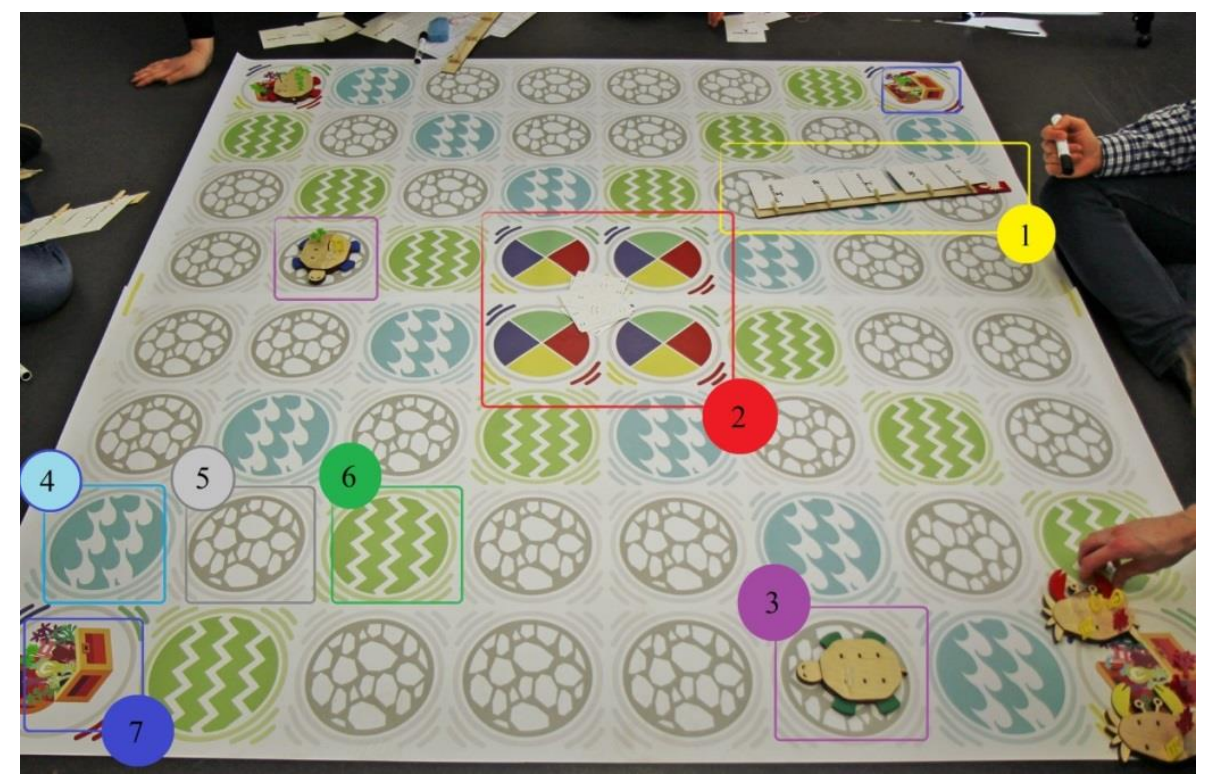

Figure 1. The Treasure Hunt game (1. Sequence board, 2. Game starting points, 3. Game pieces, 4. Water grid, 5. Stone grid, 6. Grass grid, 7. Treasure collection location).

Table 2. The Treasure Hunt game cards

\begin{tabular}{|c|c|c|}
\hline \multicolumn{2}{|c|}{ Motion command cards } & \multirow[b]{2}{*}{ Event cards } \\
\hline Crabs & Turtles & \\
\hline $\begin{array}{l}\operatorname{turn} \curvearrowright{ }^{\circ} \\
\text { turn } \curvearrowleft- \\
\text { walk left } \_ \\
\text {walk right } \\
\text { repeat } 2\end{array}$ & $\begin{array}{l}\text { turn } \curvearrowright-{ }^{\circ} \\
\text { turn } \curvearrowleft-{ }^{\circ} \\
\text { walk forward } \\
\text { walk backward } \\
\text { repeat } 2\end{array}$ & $\begin{array}{l}\text { walk forward } 2 \\
\text { walk backward } 2 \\
\text { walk left } 2 \\
\text { walk right } 2 \\
\text { turn } \curvearrowright 90^{\circ} \\
\text { turn } \curvearrowleft 90^{\circ}\end{array}$ \\
\hline
\end{tabular}

\subsubsection{Game Play and Rule}

The game is played in teams of two. Each team possesses one game piece (crab or turtle), a sequence board, five re-writable motion command cards (see Table 2), a marker, and a sponge (see Figure 3). Each turn, teams draw one more Event card from the pile (see Table 2), which they can either use in building their sequence on the sequence board or return it at the end of their turn. The goal of the game is to collect as fast as possible a specific number of food-treasures (e.g., three), which are spread across the game-board. 
pag. 30

Each team has to collect three different food items from three different treasure points on the board grid. Turtles collect magenta coloured items, while crabs collect green ones (Figure 3). To approach the treasure on the grid of the game board, teams have to structure their command cards on their sequence board and at the same time consider the respective restrictions for crabs and turtles (i.e., crabs can move only on stone and water grid squares, while turtles can move only on grass and stone grid squares). Both types of game pieces can step on all treasure locations (see Figure 2). At each turn teams have in total 6 cards from which they can use a maximum of 5 in order to build their sequence. When executing a sequence of commands users are rewarded skill badges related to their achievements. These are collected on the back of the game pieces (see Figure 3 and Scoring). The first team to fulfil the condition to win the game (e.g., collect three pieces of food) has to wait for the round to finish. In case there is another team to achieve the winning condition within the same round, the winner is determined by the number of badges collected.

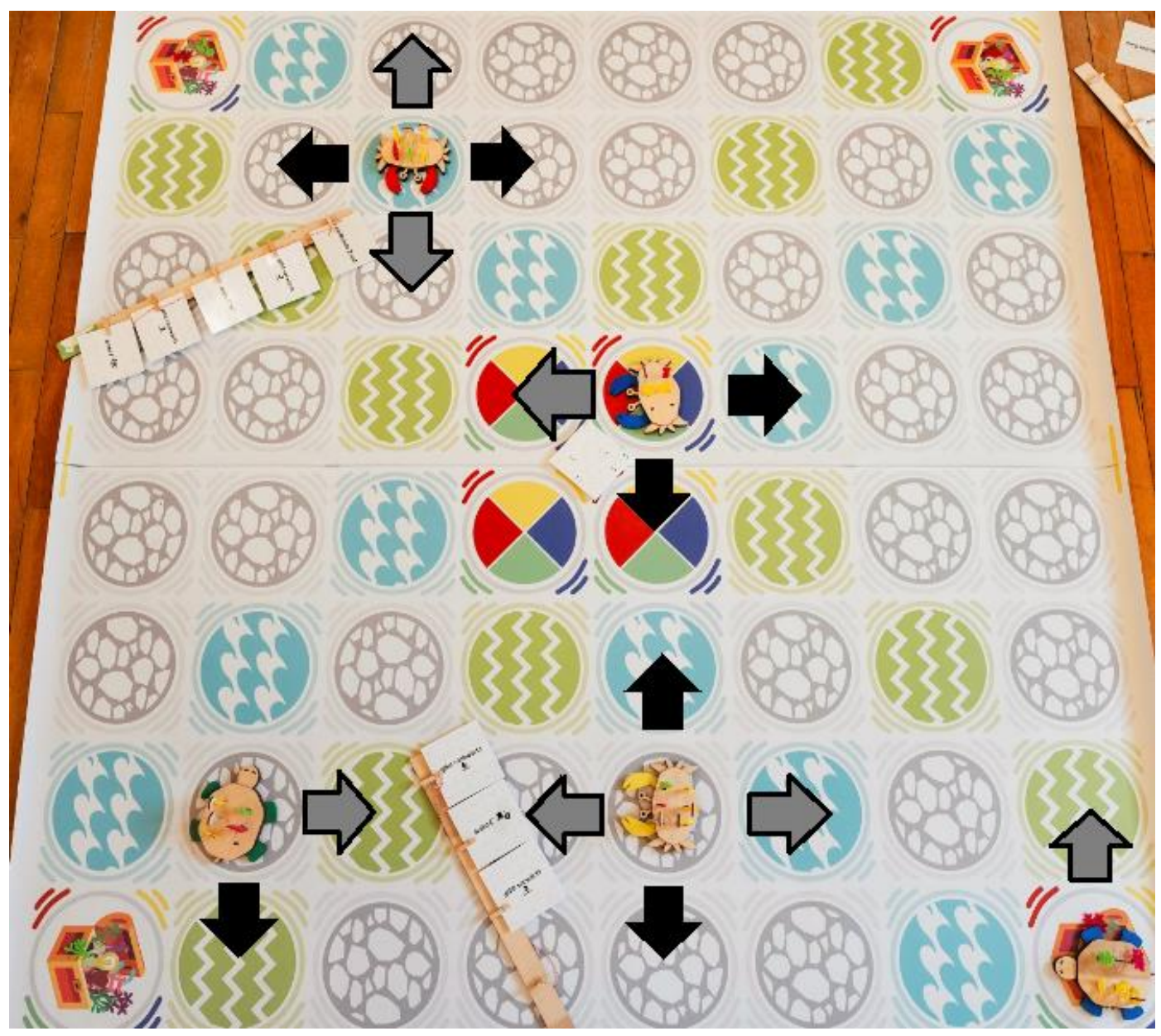

Figure 2. The Treasure Hunt game restrictions in movement for a certain scenario (black arrows: movements normally allowed for each game piece; grey arrows: bonus movements for each game piece due to special cards).

\subsubsection{Scoring}

While playing the game, teams collect inventory items that they carry on the back of their game pieces. These inventory items include food-treasure items and skill badges. There are 6 different food-treasure items, differentiated both by shape and colour. Green food items represent earth growing food and magenta ones represent seaweed to-be-collected by turtles and crabs, respectively. There are 4 different skill badges (see Figure 3 ) that 
teams can collect at the end of each turn: (i) sequence-, (ii) loop-, (iii) angular degree-, and (iv) efficiency-badges. Teams get a sequence badge each time they succeed in forming and executing a correct algorithm reflecting a sequence of at least 3 commands. They get a loop or angular degree badge each time they succeed in using correctly and meaningfully a loop card or a turning card, respectively. Furthermore, in case teams build and execute correctly an algorithm consisting of a sequence of 5 commands, they get an efficiency badge, because using 5 cards in an efficient combination is difficult. At the end of the game scores are summed up based on both food-treasure items collected and on the number of skill badges. Winner of the game, however, is considered the team that first collects three food-treasure items.

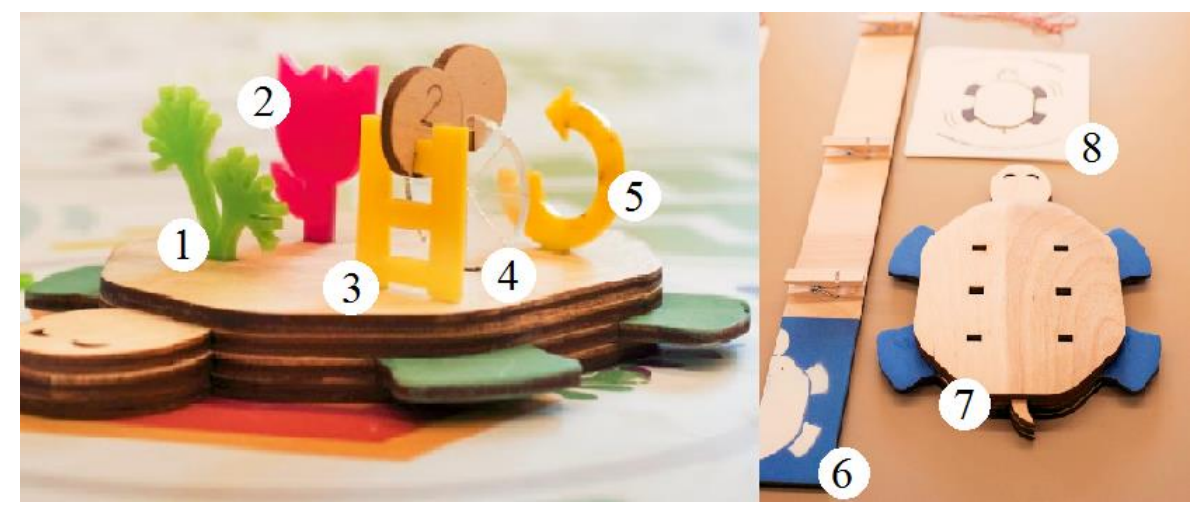

Figure 3. The Treasure Hunt inventory items (1. Food treasure for crabs, 2. Food treasure for turtles, 3. Sequence badge, 4. Anglular degree badge, 5. Loop badge, 6. Sequence board, 7. Game piece, 8. Re-writable motion command cards)

\subsection{The Race}

The Race is the second game of Crabs \& Turtles. In this game, users have to reach the end first by solving and handling math related riddles and events. To do so, players have to manipulate constants and changing values of variables or make decisions based on conditionals. Overall, this game focuses more on CT abilities related to mathematical skills. In particular, understanding of constants and variables, operators, and events handling, addition and multiplication, as well as simple conditional understanding are the main abilities to be acquired or trained, respectively, in this game. 


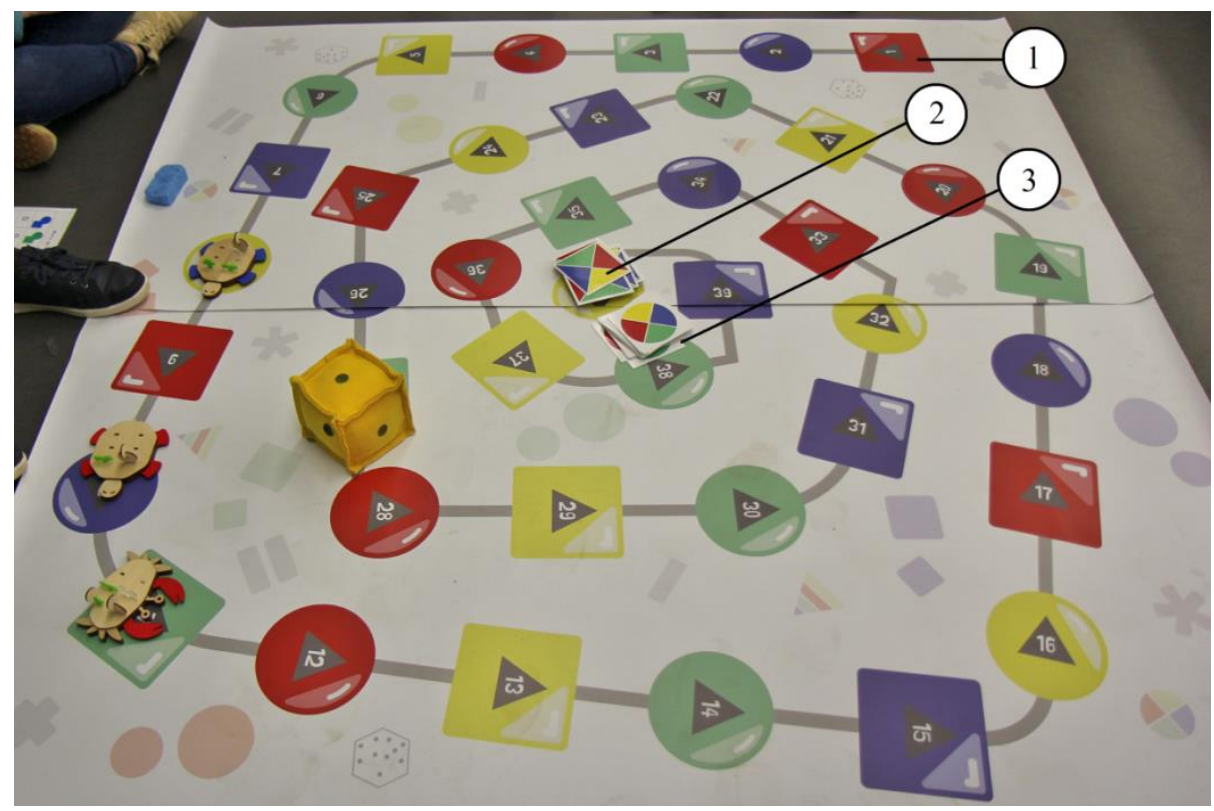

Figure 4. The Race game (1. Starting point, 2. Event cards, 3. Riddle cards).

\subsubsection{Learning Objectives}

Main aim of the game is the general introduction of concepts shared between coding and math. Players are introduced to variables, constants, operators, and conditionals. The game focuses on training to handle values within simple and more complex arithmetic operations that contain additions, subtractions, and multiplications. Operations consist of visual representations of variables and constants (see Figure 5), so that the players get familiar with recognizing symbolic representations of things, get used to an abstract form of reading instructions, and handling events that allow for generalization, as it happens in actual coding.

The game is played in teams of two and each team possesses one out of two types of game pieces, a re-writable variable/notes board, a marker, and a sponge. The game starts with all the game pieces placed at the starting point on the game board (see Figure 4). In each round, each team rolls a dice and moves as many steps forward as shown on the dice. In case players move their game piece to a circle shape they receive a card from the pile of circle cards (Riddle cards), otherwise they receive a card from the pile of square cards (Event cards). Circle cards contain riddles of equations that players have to solve. An example is presented in Figure 5 (lower panel), where the riddle asks the solution of an addition. The triangle represents the number of the step on which the game piece is currently standing, the colourful circle and square, respectively, indicate the value of the colour variable on which the game piece stands and the third part of the addition is the value of the dice in the current turn. In the example depicted in Figure 5, assuming that the red crab of Figure 4 is playing and the team rolls the dice and it shows 1, the crab will have to move forward one step. From the green square point number 11 it will move on one step to the red circle point number 12 . The team will take a Riddle card and will have to solve the riddle. The addition consists of the value of the grey triangle, which is currently 12 , the value of the red colour variable that has been influenced by all previous turns so far and the value of the dice, which for this turn was 1. 


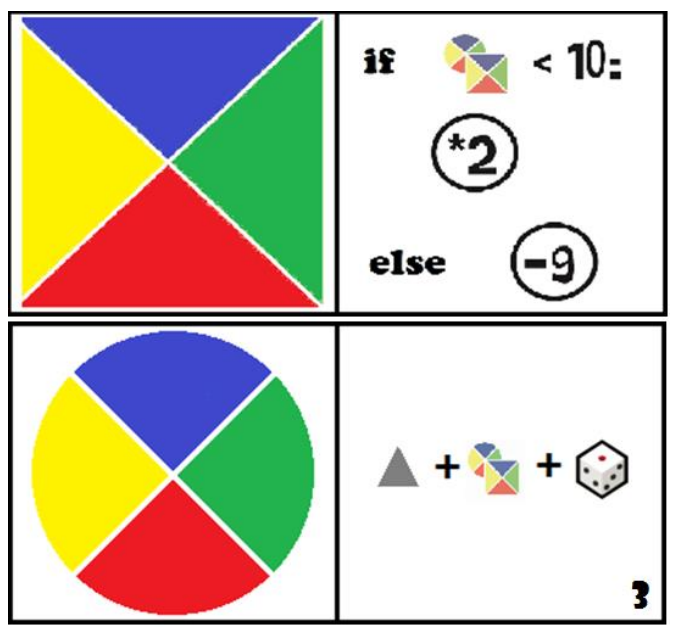

Figure 5. The Race game, an Event card example (upper panel, colorful square; left: cover, right: content) and a Riddle card example (lower panel, colorful circle; left: cover, right: content).
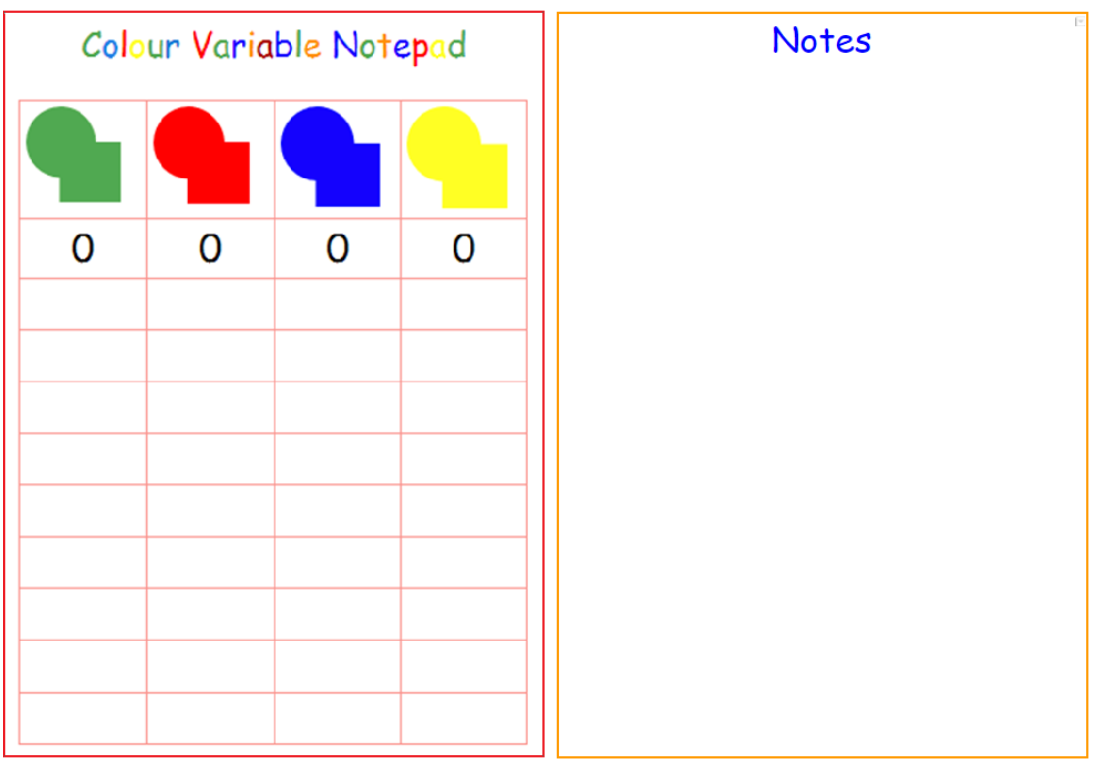

Figure 6. The Race game, the re-writable variable board.

\subsubsection{Game Play and Rules}

When the team solves the riddle correctly they can move forward a defined number of steps, written on the lower right corner of the card (in the example of Figure 5 the steps forward are 3). The more difficult a riddle, the more steps the team is allowed to move forward. The difficulty of the riddles arises from the number of operators, variables, and constants in the mathematical expression (polynomial) of each riddle. For example, a mathematical expression that involves both variables and constants is considered more difficult than a mathematical expression consisting only from constants. Square cards, in contrast, contain events that change the value of a variable. These changes need to be calculated from simple numerical operations and/or conditionals specified on each square card. For example in Figure 5, the Event card describes a conditional event, in which the player has to recalculate the value of the colour variable his/her game piece has landed on. When, for example, the game piece has landed on the red colour and at this point of the game the red colour variable has a value lower than 10 , then the new value that the red colour variable will receive is calculated from a multiplication of the current value by 2 . 
pag. 34

Otherwise, the new value of the variable would be the current one reduced by 9 . When variable values are handled correctly, players move forward one step and wait for their next turn. To keep track of the changing colour variable values within the game, teams use the rewritable variable board (see Figure 6). It is also used as a re-writable note board for math calculations. Overall aim of this game is to reach the final point in the centre of the game board as fast as possible. While teams solve riddles and interact with events they collect specific skill badges (see Scoring) that they collect on the back of their game pieces. The first team to reach the centre of the spiral has to wait for the round to finish. In case there is another team to reach the end of the race within the same round, the winner is determined based on the number of badges collected.

\subsubsection{Scoring}

Inventory items in The Race consist of 6 different skill badges: (i) addition-, (ii) subtraction-, (iii) multiplication-, (iv) variable-, (v) constant-, and (vi) conditional-badge. Teams get a variable or a constant badge each time they succeed in recognizing and handling a variable, and a constant, respectively. They also get an addition, subtraction, or multiplication badge each time they solve the respective operation requested on a circle card correctly. Each time a team handles an Event card that indicated a value change of a conditional variable (see Figure 5, upper panel) correctly, it gets a conditional badge as well. At the end of the game scores are summed up based on the inventory items of each team. Winner of the game is the first team to reach the end of the game board with the most badges collected.

\subsection{Patterns}

Patterns is a card game, played by individual players and not teams. In this game, players have to find patterns and match cards by certain rules, as fast as possible. This procedure is closely related to pattern recognition processes that are necessary in coding, for instance, when decomposing problems, generalizing solutions, and forming loops.

\subsubsection{Learning Objectives}

The game is an introductory activity to the concept of patterns. Patterns are crucial concepts in CT. They are used both in identifying abstractions and generalization [41]. This game aims at training to recognize shape and colour patterns by following certain rules.

\subsubsection{Game Play and Rules}

The game is structured in two parts and needs a game master that will act as the card dealer. Half of the cards lay open in arbitrary order on the floor, while the other half of the cards is being gradually revealed by the game master in random order. Players begin playing with no cards and start collecting cards each time they find a correct pair. In the first part (Figure 7, left) players have to find and match two cards according to the pattern depicted on them as fast as possible. In order for a player to claim a pair, he/she has to be the fastest in turn-taking from the game-master, by raising hand. The game master reveals cards one after the other and the first player to recognise and match two cards correctly wins the paired card and thus a point. When a card is revealed but not correctly paired, the game master hides it again and opens a new one. To match rectangle cards, players have to follow three rules: i. cards should share the same pattern order (e.g., star, triangle, circle, square, see Figure 8 left panel), ii. they should not have the same colour at the same position (e.g., in Figure 8 colour order of the matching card should not be bluegreen-red-blue), and iii. cards should share the same colour palette (e.g. in Figure 8 only the colours blue, green and red). In the second part of the game (Figure 8, right panel) players should read the shape and colour code of the square cards correctly and match them to the correct rectangle card (Figure 8 left) as fast as possible. The square card's 
code is read clockwise or counterclockwise, starting from the indicated shape and following the colour order directed by an arrow (i.e., starting with a blue star, going clockwise to green, red, and blue again, which matches the shape and colour order of the rectangle card, left panel). When players match a rectangle to a square card correctly they win the square card.

\subsubsection{Scoring}

In this game, players gain cards when they match cards in pairs correctly. When a pair is correctly paired the player to claim it collects the respective cards from the floor. At the end of the game, players count the number of cards they collected while playing. The player who won the most cards wins the game.

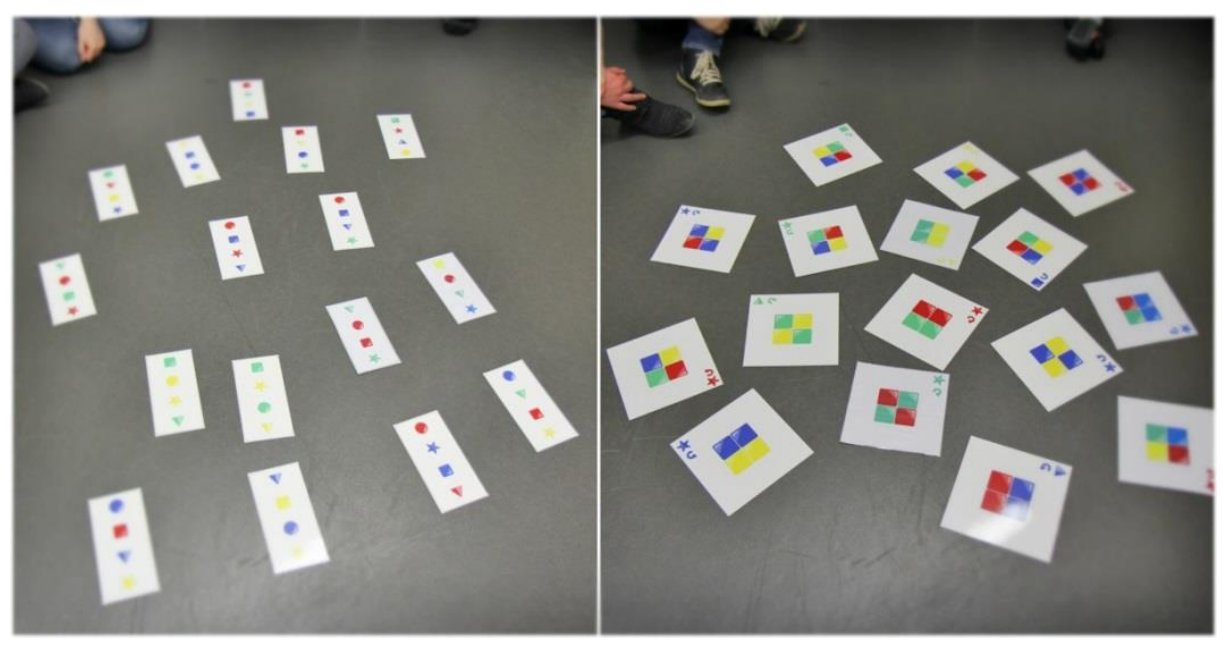

Figure 7. Patterns game.

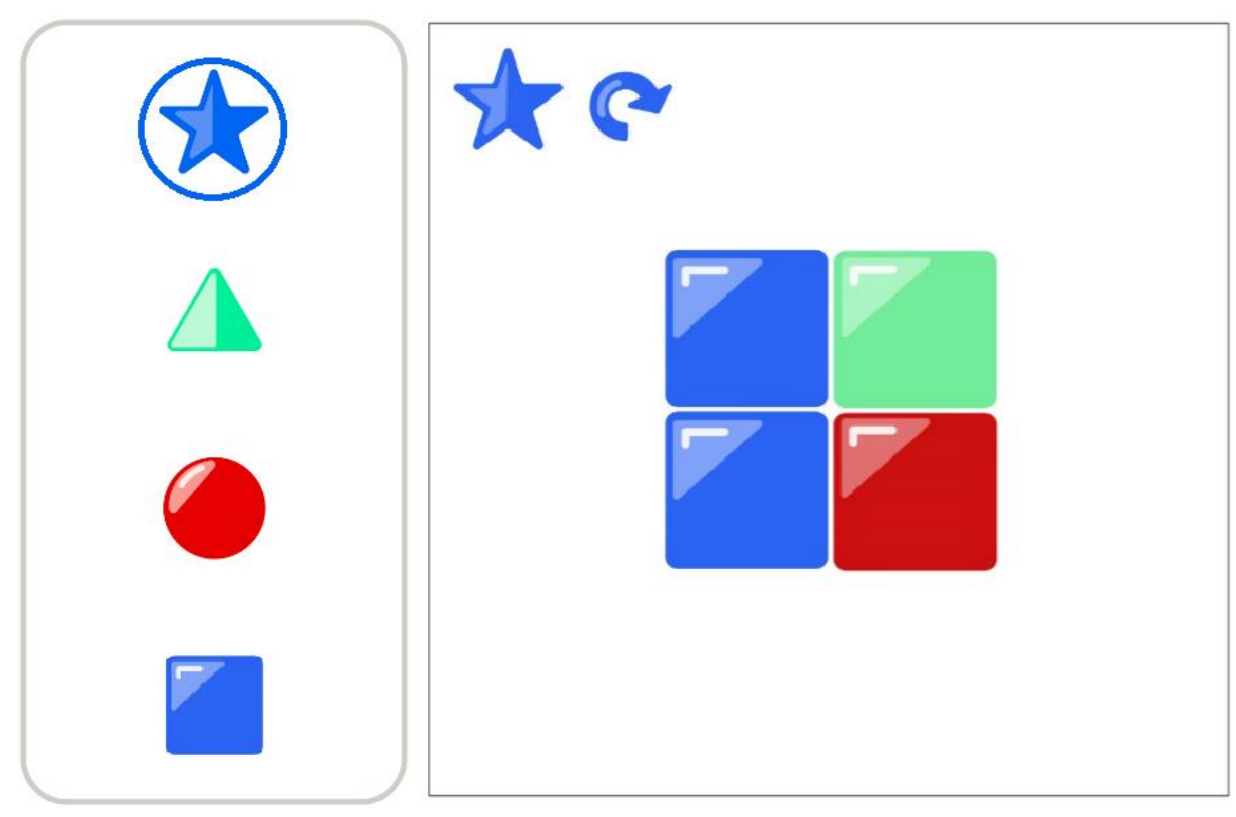

Figure 8. Patterns game cards; left panel: rectangle card; right panel: square card. 
Regular user tests are an important step during the development of a new game, educational or not. Here, we describe results of a 2-phase user test evaluating game experience of above described games. Our main focus was on investigating game experience quantitatively and to gather qualitative feedback of participants to identify potential dysfunctionalities during game-play, which then can be addressed before testing it with our main target group of primary school children. The main objective of Phase 1 was to evaluate overall game experience of Crabs and Turtles as indicated by users. This was followed by a more in-depth analysis of game experience in Phase 2, which investigated the games The Treasure Hunt, The Race, and Patterns subsumed in Crabs and Turtles separately. Moreover, to further validate the current approach, participants in Phase 1 consisted of regular university students, while in Phase 2 relevant stakeholders were tested, that is, teachers, computer science instructors, and professional gamification experts.

\subsection{Study Phase 1}

\subsubsection{Participants}

We collected data from 17 adult university students from the University of Tuebingen, aged between 22 and 33 (mean $=27.12, S D=3.20)$. Students participated voluntarily.

\subsubsection{Procedure and Materials}

In 3 separate 2-hour gaming sessions we evaluated game experience of participants. In each session all 3 games of Crabs and Turtles were played. After a short introduction into the aim of the session, participants were asked to fill in an optional photographic release form. Before participants started playing each of the games, we provided oral and visual instructions. After playing all 3 games, participants were asked to fill in the Game Experience Questionnaire-GEQ [40]. We used the English version of the Core (33 items) and the Social Presence (17 items) modules to assess overall game experience. The Core module consists of seven subscales addressing i. Immersion, ii. Flow, iii. Competence, iv. Positive Affect, v. Negative Affect, vi. Tension, and vii. Challenge. The Social Presence module consists of three subscales assessing i. Empathy, ii. Negative Feelings, and iii. Behavioural Involvement. For each subscale we used the average scores of the respective items as dependent variable. Each item had to be responded to on a 5-point Likert-scale (1 $=$ not at all; $2=$ slightly; $3=$ moderately; $4=$ fairly; $5=$ extremely). For example, the first item of the Core module reads as follows: "I felt content" and participants had to rate their experience of content on the aforementioned Likert scale by crossing an answer from 1 to 5 (e.g. crossing 2 would mean "I felt slightly content").

Moreover, we used 4 additional items to further evaluate overall game experience, which also employed a 5-point Likert-scale: Q1. I would explain my experience as playing; Q2. I would explain my experience as learning $(\mathrm{Q} 1 \& \mathrm{Q} 2: 1=$ not at all; $2=$ not really; $3=$ undecided; $4=$ somewhat; $5=$ very much); $Q 3$. I would recommend the games to a friend; Q4. I would like to play the games again in the future $(\mathrm{Q} 3 \&$ Q4: $1=$ not at all; $2=$ not really; $3=$ undecided; $4=$ likely; $5=$ very likely). Those 4 items were added to the questionnaire with the intention to measure the perception of the game as learning and/or playing, as the GEQ questionnaire aims at evaluating game experience more broadly and not game experience for educational games in particular.

Finally, 5 more items were used to evaluate specific design elements of the game, i.e. board, cards, game pieces, inventory items, and rules, again using a 5-point Likert-scale ( 1 = not at all; $2=$ slightly; $3=$ moderately; $4=$ fairly; $5=$ extremely). Moreover, every session included an open discussion part to gather qualitative feedback from the participants. 


\subsubsection{Results}

Game experience: Mean values of GEQ subscales were considered to reflect game experience in this phase. We used a conservative approach of analysing each subscale by conducting one sample $t$-test comparing means of subscale ratings of the middle value of the scale $(3=$ mediocre $)$ of the 5-point Likert scale. Descriptive results and inferential statistics of Core and Social Presence subscales are summarized in Table 3 below. Participants' ratings of the games on the Competence, Sensory \& Imaginative Immersion, and Positive affect subscales of the Core module were significantly higher than mediocre (see Table 3). In contrast, ratings on the Tension/Annoyance, Challenge, and Negative Affect subscales of the Core module and the Negative Feelings and Behavioural Involvement subscales of the Social Presence module were significantly lower than mediocre (see Table 3). We did not observe significant differences to mediocre for the subscale Flow of the Core module and the subscale Empathy of the Social Presence module.

Table 3. Mean Scores for Core Module and Social Presence Module of GEQ at

\begin{tabular}{|c|c|c|c|c|c|c|c|}
\hline GEQ modules & mean & $S D$ & $d f$ & $t$ & $p$ & $\alpha$ & $\alpha^{*}$ \\
\hline \multicolumn{8}{|l|}{ Core } \\
\hline Competence & 3.72 & .90 & 16 & 3.30 & 0.005 & .913 & .826 \\
\hline $\begin{array}{l}\text { Sensory \& Imaginative } \\
\text { Immersion }\end{array}$ & 3.63 & .73 & 16 & 3.59 & 0.002 & .783 & .891 \\
\hline Flow & 3.02 & .83 & 16 & 0.12 & 0.908 & .844 & .866 \\
\hline Tension/Annoyance & 1.29 & .37 & 16 & -18.99 & 0.001 & .402 & .811 \\
\hline Challenge & 2.38 & .65 & 16 & -3.95 & 0.001 & .735 & .745 \\
\hline Negative affect & 1.84 & .53 & 16 & -9.04 & 0.001 & .456 & .712 \\
\hline Positive affect & 4.19 & .46 & 16 & 10.76 & 0.001 & .770 & .797 \\
\hline \multicolumn{8}{|l|}{ Social Presence } \\
\hline Empathy & 3.27 & .60 & 16 & 1.89 & 0.077 & .779 & .886 \\
\hline Negative Feelings & 2.08 & .73 & 16 & -5.17 & 0.001 & .876 & .860 \\
\hline $\begin{array}{l}\text { Behavioural } \\
\text { Involvement }\end{array}$ & 2.47 & .73 & 16 & -3.00 & 0.008 & .829 & .711 \\
\hline
\end{tabular}

Different from the GEQ data, for which we conducted $t$-tests on averaged ratings for the different subscales, differentiating aspects for overall experience and specific design elements meant conducting $t$-tests against mediocre on the data of individual items. Therefore, the respective results should be interpreted more cautiously.

Overall experience: Participants perceived their experience as somewhat playing (Q1: mean $=4.18, S D=.73 ; t(16)=6.67, p<0.001)$ as indicated by a rating significantly above "undecided", but not so much as a learning experience $(\mathrm{Q} 2$ : mean $=3.35, S D=$ $1.22 ; t(16)=1.19, p=0.251)$. Participants reported that they would likely to very likely recommend the game to a friend $(\mathrm{Q} 3:$ mean $=4.53, S D=.72 ; t(16)=8.79, p<0.001)$ and would likely play the game again in the future $(\mathrm{Q} 4:$ mean $=4.18, S D=.64 ; t(16)=7.63, p$ $<0.001)$ as reflected by ratings significantly above "undecided".

Evaluation of specific design elements: The five different design elements measured by the questionnaire scored a mean of $4.46(S D=.44)$ on the 5-point Likert scale. More specifically, users rated each design element (Board: mean $=4.5, S D=.61, t(16)=10.10$, $p<0.001$; Cards: mean $=4.38, S D=.70, t(16)=8.15, p<0.001$; Game pieces: mean $=$ $4.88, S D=.33, t(16)=23.38, p<0.001$; Inventory items: mean $=4.19, S D=.81, t(16)=$ $6.06, p<0.001$, and Rules: mean $=4.38, S D=.78, t(16)=7.26, p<0.001$ significantly above mediocre. The ratings of one participant were missing for the design module of the questionnaire and were replaced with the mean of the sample.

Internal consistency of GEQ as reported by [40] and reflected by Cronbach's alpha is given in Table 3 (column $\alpha^{*}$ ). In addition, Cronbach's alpha as obtained in the current 
pag. 38

study is also reported in Table 3 (column $\alpha$ ). The observed internal consistency indicated acceptable reliability for most subscales with $\alpha>.70$. However, this was not the case for subscales Tension/Annoyance and Negative affect of the GEQ Core module.

Qualitative feedback: Participants' impressions on the games were positive and encouraging. Their comments in Phase 1 led to several design changes regarding the game mechanisms. For instance, it became clear that instructions were not always clear in the way they were presented to players. Moreover, participants reported some in-game unbalances caused by a high dependency on chance. For example, in The Treasure Hunt the command card for loops was part of the Event cards which are taken at each turn by chance from the pile. That was affecting teams' strategy to prepare their moves. Therefore, in Phase 2 this card was given as a Motion command card to each team from the beginning of the game. Reported unbalances of this kind were adjusted by excluding and/or adding specific kinds of cards (i.e. in The Treasure Hunt, in The Race) in an effort to balance chance and skill driven strategies during gameplay. Participants also criticised other dysfunctionalities, like long waiting in between turns or very limited step movement. We addressed this by introducing a time limit for each turn using a 3-minute hourglass and by excluding the use of a dice for determining the number of steps allowed for a team to move per turn (i.e. in The Treasure Hunt). These problems were addressed and fixed before starting the assessment of each game separately in Phase 2.

\subsection{Study Phase 2}

\subsubsection{Objective and Procedure}

The second phase of the adult sessions aimed at a more in-depth evaluation of game experience by investing each game separately. This phase also consisted of 3 sessions (á 2-3 hours), one hosted by the $11^{\text {th }}$ Thessaloniki Gamification Meet-up and two independently organised events. The procedure followed in this phase was comparable to that of Phase 1 with the difference that participants had to fill in the respective questionnaires separately for each game.

\subsubsection{Participants}

Data were collected from 19 participants in total, aged between 25 and 52 ( mean $=31.43$, $S D=6.17)$. There were 10 female and 9 male participants including teachers, computer science instructors, professional gamification designers, etc. Due to technical and organizational problems not all participants were able to play all three games. That is, 15 played all three games, 2 participants played only the first game, 1 participant played only games 1 and 2, and 1 participant only games 2 and 3 .

\subsubsection{Materials}

We used the same questionnaires and additional items as in Phase 1. However, participants had to answer the questions for each game separately. The questionnaire was completed in its original English version from 13 participants. 6 participants felt more confident completing it in its Greek translation.

\subsubsection{Results}

We applied the same conservative approach of analysing GEQ Core and Social Presence subscales. However, in Phase 2 we were able to conduct the analyses for each game. Descriptive results and inferential statistics are reported in Table 4. There were few missing values, which were replaced by the mean score for the respective item computed from the other participants.

Game experience - The Treasure Hunt: Participants rated this game significantly above mediocre on the subscales Competence, Sensory \& Imaginative Immersion, and Positive affect of the Core module and Empathy of the Social Presence module. In contrast, ratings were significantly below mediocre for the subscales Tension/Annoyance, 
Challenge, and Negative Affect of the Core module, as well as for the Negative Feelings and Behavioural Involvement subscales of the Social Presence module. We did not find a significant difference from mediocre for the Flow subscale of the Core module.

Game experience - The Race: Participants' ratings for this game were significantly above mediocre for the Competence, Sensory \& Imaginative Immersion, and Positive affect subscales of the Core module and the Empathy subscale of the Social Presence module. Contrarily, participants rated the game significantly below mediocre on the subscales Tension/Annoyance, Challenge, and Negative Affect of the Core module and the Negative Feelings subscale of the Social Presence module. Again, we did not find a significant difference to mediocre for the Flow subscale of the Core module and the Behavioural Involvement subscale of the Social Presence module.

Games experience - Patterns: Largely similar to the results for the other games, participants' ratings for Patterns was significantly above mediocre for the Competence, Sensory \& Imaginative Immersion, and Positive affect subscales of the Core module and the Empathy subscale of the Social Presence module. Again, ratings for the Tension/Annoyance, Challenge, and Negative Affect subscales of the Core module and the Negative Feelings and Behavioural Involvement subscales of the Social Presence module were significantly below mediocre. Also, we did not find a significant difference to mediocre for the subscale Flow of the Core module as well as the subscales Empathy and Behavioural Involvement of the Social Presence module.

Table 4. Mean Scores for Core Module and Social Presence Module of GEQ at Phase 2, per game-based activity.

\begin{tabular}{|c|c|c|c|c|c|c|c|}
\hline \multicolumn{8}{|c|}{ The Treasure Hunt } \\
\hline GEQ modules & mean & $S D$ & $d f$ & $t$ & $p$ & $\alpha$ & $\alpha^{*}$ \\
\hline \multicolumn{8}{|l|}{ Core } \\
\hline Competence & 3.70 & .75 & 17 & 3.98 & 0.001 & .794 & .826 \\
\hline Sensory \& Imaginative Immersion & 4.04 & .71 & 17 & 6.19 & 0.001 & .816 & .891 \\
\hline Flow & 3.17 & .92 & 17 & 0.77 & 0.454 & .764 & .866 \\
\hline Tension/Annoyance & 1.51 & .48 & 17 & -13.19 & 0.001 & .130 & .811 \\
\hline Challenge & 2.21 & .54 & 17 & -6.17 & 0.001 & .576 & .745 \\
\hline Negative affect & 1.42 & .37 & 17 & -17.97 & 0.001 & .300 & .712 \\
\hline Positive affect & 4.29 & .51 & 17 & 10.63 & 0.001 & .800 & .797 \\
\hline \multicolumn{8}{|l|}{ Social Presence } \\
\hline Empathy & 3.48 & .88 & 17 & 2.32 & 0.033 & .885 & .886 \\
\hline Negative Feelings & 2.04 & .87 & 17 & -4.69 & 0.001 & .795 & .860 \\
\hline Behavioural Involvement & 2.49 & .92 & 17 & -2.36 & 0.030 & .835 & .711 \\
\hline \multicolumn{8}{|c|}{ The Race } \\
\hline GEQ modules & mean & $S D$ & $d f$ & $t$ & $p$ & $\alpha$ & $\alpha^{*}$ \\
\hline \multicolumn{8}{|l|}{ Core } \\
\hline Competence & 3.64 & .88 & 16 & 2.96 & 0.009 & .635 & .826 \\
\hline Sensory \& Imaginative Immersion & 3.67 & .86 & 16 & 3.21 & 0.005 & .858 & .891 \\
\hline Flow & 3.28 & 1.14 & 16 & 1.02 & 0.324 & .924 & .866 \\
\hline Tension/Annoyance & 1.84 & 1.09 & 16 & -4.39 & 0.001 & .830 & .811 \\
\hline Challenge & 2.42 & .73 & 16 & -3.24 & 0.005 & .657 & .745 \\
\hline Negative affect & 1.69 & .67 & 16 & -8.05 & 0.001 & 639 & .712 \\
\hline Positive affect & 4.14 & .78 & 16 & 6.01 & 0.001 & .894 & .797 \\
\hline \multicolumn{8}{|l|}{ Social Presence } \\
\hline Empathy & 3.69 & .84 & 16 & 3.38 & 0.004 & .862 & .886 \\
\hline Negative Feelings & 2.26 & .69 & 16 & -4.44 & 0.001 & .589 & .860 \\
\hline Behavioural Involvement & 2.55 & 1.06 & 16 & -1.76 & 0.097 & .876 & .711 \\
\hline \multicolumn{8}{|c|}{ Patterns } \\
\hline GEQ modules & mean & $S D$ & $d f$ & $t$ & $p$ & $\alpha$ & $\alpha^{*}$ \\
\hline \multicolumn{8}{|l|}{ Core } \\
\hline Competence & 3.70 & .90 & 15 & 3.09 & 0.007 & .820 & .826 \\
\hline Sensory \& Imaginative Immersion & 3.84 & .72 & 15 & 4.66 & 0.001 & .849 & .891 \\
\hline Flow & 3.90 & .82 & 15 & 4.41 & 0.001 & .772 & .866 \\
\hline
\end{tabular}


pag. 40

\begin{tabular}{lllllllll} 
Tension/Annoyance & 1.73 & .84 & 15 & -6.08 & 0.001 & .675 & .811 \\
Challenge & 3.18 & .80 & 15 & 0.87 & 0.397 & .706 & .745 \\
Negative affect & 1.32 & .51 & 15 & -13.21 & 0.001 & .487 & .712 \\
Positive affect & 4.41 & .65 & 15 & 8.68 & 0.001 & .785 & .797 \\
\hline Social Presence & & & & & & & & .846 \\
\hline Empathy & 3.27 & .93 & 15 & 1.47 & 0.162 & .840 & .886 \\
Negative Feelings & 2.08 & 1.03 & 15 & -3.47 & 0.003 & .821 & .860 \\
Behavioural Involvement & 2.47 & 1.28 & 15 & -1.11 & 0.285 & .933 & .711 \\
\hline
\end{tabular}

Again, analysis of overall experience and specific design elements required us to run $t$-tests on data from individual items. Thus, the respective results should be interpreted more cautiously.

Overall Experience: Participants experienced The Treasure Hunt very likely as playing $\left(\mathrm{Q} 1\right.$ : mean $\left.=4.72, S D=.46 ; t_{(17)}=15.85, p<0.001\right)$ and somewhat as learning $\left(\mathrm{Q} 2:\right.$ mean $\left.=4.22, S D=.94 ; t_{(17)}=5.50, p<0.001\right)$ as reflected by ratings significantly above "undecided". Additionally, participants reported that they would very likely recommend the game to a friend $\left(\mathrm{Q} 3\right.$ : mean $\left.=4.50, S D=.71 ; t_{(17)}=9.00, p<0.001\right)$, and would likely play the game again in the future $(\mathrm{Q} 4$ : mean $=4.22, S D=1.06 ; t(17)=4.89$, $p<0.001$ ), which was also supported by ratings significantly above "undecided".

For The Race ratings significantly above "undecided" indicated that participants rated their game experience very likely as playing $\left(\mathrm{Q} 1\right.$ : mean $=4.53, S D=.72 ; t_{(16)}=8.79, p<$ $0.001)$, and somewhat as learning $\left(\mathrm{Q} 2\right.$ : mean $\left.=4.24, S D=1.03 ; t_{(16)}=4.93, p<0.001\right)$. Furthermore, ratings significantly above "undecided" substantiated that they would likely recommend the game to a friend (Q3: mean $\left.=4.18, S D=.73 ; t_{(16)}=6.67, p<0.001\right)$, and also would likely play it again in the future $\left(\mathrm{Q} 4:\right.$ mean $=4.29, S D=.69 ; t_{(16)}=7.78, p<$ $0.001)$

Finally, participants perceived the Patterns game very likely as a playing experience $\left(\mathrm{Q} 1:\right.$ mean $\left.=4.69, S D=.79 ; t_{(15)}=8.51, p<0.001\right)$ and likely as learning $(\mathrm{Q} 2:$ mean $=$ $\left.4.06, S D=1.00 ; t_{(15)}=4.26, p<0.001\right)$, which was again reflected by ratings above "undecided". Moreover, according to ratings above "undecided", participants reported that they would very likely recommend it to a friend $\left(\mathrm{Q} 3\right.$ : mean $=4.56, S D=.62 ; t_{(15)}=$ 9.93, $p<0.001)$, and also play it again (Q4: mean $\left.=4.56, S D=.73 ; t_{(15)}=8.60, p<0.001\right)$.

Evaluation of specific design elements: In the current phase, the five design elements were evaluated individually. For the two first games all five design elements were assessed. The design elements of Games 1 and 2 scored a mean of $4.37(S D=.47)$ and $4.03(S D=.72)$ respectively, on the 5-point Likert scale. Game 3 design elements were scored a mean of $4.49(S D=.51)$. More specifically, users liked all five design elements of The Treasure Hunt (Board: mean $=4.25, S D=.94, t_{(17)}=5.65, p<0.001$; Cards: mean $=$ 4.13, $S D=.83, t_{(17)}=5.74, p<0.001$; Game Pieces: mean $=4.80, S D=.38, t_{(17)}=20.33, p$ $<0.001$; Inventory items: mean $=4.63, S D=.58, t_{(17)}=11.86, p<0.001$ and Rules: mean $\left.=4.06, S D=1.00, t_{(17)}=4.52, p<0.001\right)$ significantly above than mediocre. Same positive scores received all the five design elements of The Race (Board: mean $=3.69, S D$ $=1.3, t_{(16)}=2.17, p=0.046$; Cards: mean $=4.19, S D=1.01, t_{(16)}=4.83, p<0.001$; Game pieces: mean $=4.38, S D=.93, t(16)=6.12, p<0.001$; Inventory items: mean $=4.13, S D$ $=.93, t_{(16)}=5.01, p<0.001$ and Rules: mean $\left.=3.75, S D=1.15, t_{(16)}=2.70, p=0.016\right)$ as reflected by ratings significantly above mediocre. The two design elements in the questionnaire for Patterns scored also positively) as indicated by ratings significantly above mediocre (Cards: mean $=4.38, S D=.72, t_{(15)}=7.65, p<0.001$; and Rules: mean $=$ $\left.4.60, S D=.49, t_{(15)}=13.06, p<0.001\right)$. The missing values for this part of the questionnaires were managed as before. There were two participants that did not fill in all the five questions concerning the design evaluation of the first game. Their missing values, as well as one single missing value from a third participant, were replaced by the mean scores of each single item. In the second game, one participant's responses were missing for all the 5 design elements.

For Phase 2, reliability analyses run separately for each GEQ subscale game again indicated acceptable reliability for most subscales with $\alpha>.70$ (see Table 4, column $\alpha$ ). 
However, this was not case for the subscales Competence (in The Race), Tension/Annoyance (in The Treasure Hunt and Patterns), Challenge (in The Treasure Hunt and The Race), Negative affect (The Treasure Hunt, The Race and Patterns) and Negative feelings (in The Race). Those results may be affected by the rather small number of participants in our sample.

Qualitative feedback: Participants' impressions on the games were positive and promising for the content and the mode of the games. Their comments in Phase 2 were taken into consideration and led to minor changes in the latest version of the games. For instance, in The Treasure Hunt the maximum duration of play during a turn (3 minutes) was considered too long, thus it was reduced and limited to 1 minute. In The Race, depiction of variables on the cards was somewhat confusing, for that reason the image was slightly adjusted. In Patterns, several participants ( 2 of them with partial colour blindness) reported colour confusion while trying to recognise shapes of yellow colour. Consequently, we changed the hue of yellow colour on the cards of this game. Finally, many participants requested a cumulative score across all three games that would allow determining an overall winner of Crabs \& Turtles.

\section{Discussion}

The main aim of the present study was to describe the design and development of three unplugged games to foster computational thinking abilities in primary school children. The three games focused on different concepts relevant for computational thinking. In a 2-phase process we evaluated users' game experience. Using an iterative user-centered development process, dysfunctionalities in gameplay and shortcomings in instructions were identified and fixed during the development process. Quantitative analyses of overall (Phase 1) and game specific game experience (Phase 2) provided promising results as to the validity of our approach. In the following, we will discuss the results of phases 1 and 2 in turn.

In Phase 1 university student participants rated their overall game experience after playing all three games. Results indicated an overall positive reception of the educational games. In particular, users reported to feel competent and immersed during game play and perceived positive affect. In contrast, their GEQ ratings did neither indicate the experience of tension nor did they report to perceive negative emotions more generally. Additional analyses of overall experience further indicated that the games were primarily perceived as a playful activity and only to a lesser degree as learning. These results are in line with our objective of conveying basic concepts of computational thinking in a low threshold and game-based manner. Importantly, this is also reflected in users reported willingness to play the games again and also recommend playing the respective games to friends. Therefore, overall evaluation of the games yielded promising results about users' game experience that further backed the design of Crabs \&Turtles as a whole.

In the more in-depth analysis of each individual game in Phase 2 results of Phase 1 were substantiated as we identified similar patterns for participants' ratings of game experience. Importantly, participants with a more educational oriented background (i.e., teacher, computer science instructors, etc.) again indicated that they perceived high levels of positive emotions, competence, as well as immersion while playing each of the three games. Additionally, they reported only low perceived levels of negative emotions and tension in all three games. Interestingly, high levels of flow were only reported by participants for playing Patterns. At the same time, overall challenge was rated rather low in The Treasure Hunt and The Race, suggesting that these games in their current form might be rather easy for adult participants. This might also explain the rather mediocre perception of flow in these two games. Nevertheless, all three games were perceived as playful activities and users indicated that they would like to play again as well as recommend all of the games to their friends. Moreover, design elements of each game 
pag. 42

(i.e., game board, cards, game pieces, inventory items, rules) were rated positively throughout.

Taken together, results of Phase 1 as well as Phase 2 evaluations provided converging evidence on the validity of Crabs \&Turtles as an unplugged and game-based approach to convey basic concepts of computational thinking - both overall (Phase 1) but also when considered separately for the three games The Treasure Hunt, The Race, and Patterns. As such, this indicated that we took the first steps in developing an educational game. The design and CT concepts employed in all three games were derived from recent research [3][30][42] which is a first crucial step in developing educational (board) games. From the beginning, we used an iterative user-centred development procedure, starting with pilot tests with primary school children our main target group. However, before starting a comprehensive evaluation of cognitive effects and learning outcomes due to the three games in our main target group, we aimed at optimizing game experience and in-game procedures. Therefore, we employed a 2-phase evaluation of game experience in adults as reported in the current article. Overall and specific game experience was consistently positive as indicated by participants' ratings in both phases. Moreover, qualitative feedback by users helped to further optimize gameplay and mechanics. Adult participants, in particular the specialized group of teachers, computer science instructors, and gamification experts considered in Phase 2, was able to provide us with specific and tothe-point feedback to further develop and improve the games and prepare them for the use in our main target group.

Based on our observations, we are confident that the employed alternation of different mechanics across the games helped to keep different personal characters (e.g. shy, extrovert, patient or impatient participant) engaged in the educational content of the game. We noted that for the mechanic of turns, seemingly more analytical and patient individuals with a focus on details, seemed to be attracted more to the gameplay in the first game (The Treasure Hunt). In contrast, in the third game (Patterns), we found that seemingly more impatient and extrovert users were highly engaged. For the second game (The Race) the mechanism of turns seemed to engage all kinds of users more equally after modification of the rules from Phase 1 to Phase 2. Another supporting example is the alternating mode of game play across games, starting with cooperation within teams and competition between teams (The Treasure Hunt and The Race) moving on to the final game with competition between all participating individuals (Patterns). This alternation of modes across games supported the collaborative introduction to the games (The Treasure Hunt and The Race), as well as the personal satisfaction of each user at the endmost of the games (Patterns).

There are limitations to the present study that need to be considered when interpreting the results and should be addressed in already planned follow-up studies to overcome these limitations. For instance, while adult participants might be well able to provide more specific feedback and are easier to recruit and test as compared to children for initial pilot tests, a comprehensive analysis of game experience and learning outcomes in the main target group is of course necessary. Therefore, such a comprehensive evaluation of our games will be our next step, with a special focus on learning outcomes (by implementing a pre-/post-test design) in addition to questionnaire data on game and learning experience.

\section{Perspectives}

Future studies will, thus, have to evaluate game experience but also learning outcomes of the three games in primary school children to appraise their educational value in fostering CT abilities. Moreover, these games will be integrated in the first three lessons of a 10 lesson CT course curriculum [13]. In this CT course, a game-based introduction of CT concepts in an unplugged manner is provided (i.e., without using a computer or other digital technology). In later lessons of the course, the very same CT concepts are picked- 
up again in the context of other educational programming environments, for instance, Scratch, Scratch for Arduino (S4A), and Roberta robot programming (for a more comprehensive description of the course curriculum see [13]). Generally, the extracurricular course primarily aims at introducing and fostering computational thinking, but not exclusively in gifted students between 7 and 9 years of age. More specifically, in a first phase the games described in this article are planned to be evaluated in 4 Academies of the Hector Children's Academy Program (HCAP) for gifted children, as one of the 10 Hector Core Courses developed by the Hector Research Institute of Education Sciences and Psychology in Germany. In a second phase the course curriculum, including the three life-size board games, will be taught in more than twenty Hector Children's Academies across Baden-Wuerttemberg, Germany.

Beside an overall evaluation of the educational value of the 3 games presented in terms of learning outcomes, we will specifically investigate whether game metrics, such as acquired badges and points, may provide a valid and reliable stealth assessment tool to allow for formative assessment of CT abilities [43]. Finally, this upcoming comprehensive evaluation aims at investigating the underlying cognitive abilities involved in CT and possible transfer effects of the training, by administering standardized psychological tests to allow for a differential view on CT [44].

\section{References}

[1] Wing, J. M., Computational Thinking, Theoretical Computer Science, Vol. 49, Nr. 3, 2006.

[2] Wang, P. S., "From Computing to Computational Thinking", 1st ed. New York: Chapman and Hall/CRC, 2015.

[3] Brennan, K., Resnick, M., "New frameworks for studying and assessing the development of computational thinking", Annual American Educational Research Association meeting, Vancouver, BC, Canada, 2012.

[4] Wing, J. M., “Computational Thinking: What and Why?", thelink - The Magaizne of the Varnegie Mellon University School of Computer Science, Nr. March 2006, 2010.

[5] Astrachan, O., Briggs, A., The CS Principles Project, ACM Inroads, Vol. 3, Nr. 2, 2012.

[6] Yadav, A., Mayfield, C., Zhou, N., Hambrusch, S., Korb, J. T., Computational Thinking in Elementary and Secondary Teacher Education, ACM Transactions on Computing Education, Vol. 14, Nr. 1, 2014.

[7] Tuomi, P., Multisilta, J., Saarikoski, P., Suominen, J., Coding skills as a success factor for a society, Education and Information Technologies, Vol. 23, Nr. 1, 2018.

[8] Brown, N. C. C., Sentance, S. U. E., Crick, T. O. M., Humphreys, S., Restart: The Resurgence of Computer Science in UK Schools, ACM Transactions on Computing Education, Vol. 14, Nr. 2, 2014.

[9] "European School Network" https://www.esnetwork.eu/

[10] "European Coding Initiative" http://www.allyouneediscode.eu/

[11] "Code.org” https://code.org./

[12] "National Science Foundation" https://www.nsf.gov/

[13] Tsarava, K., Moeller, K., Pinkwart, N., Butz, M., Trautwein, U., Ninaus, M., "Training computational thinking: Game-based unplugged and plugged-in activities in primary school". In Proceedings of the 11th European Conf. on Games Based Learning, ECGBL, October 2017.

[14] Garcia-Peñalvo, F. J., What Computational Thinking Is, Journal of Information Technology Research, Vol. 9, Nr. 3, October 2016.

[15] Boyle E.A., Hainey T., Connolly T.M., Gray G., Earp J., Ott M., Lim T., Ninaus M., Pereira J., Riberio C., An update to the systematic literature review of empirical evidence of the impacts and outcomes of computer games and serious games, Computers and Education, Vol. 94, February 2016.

[16] Plass, J. L., Homer B. D., Kinzer, C. K., Foundations of Game-Based Learning Foundations of Game-Based Learning, Educational Psychologist, Vol. 50, Nr. 4, 2015.

[17] Wouters, P., van Nimwegen, C., van Oostendorp, H., van Der Spek, E. D., A meta-analysis of the cognitive and motivational effects of serious games, Journal of Educational Psychology, Vol. 105, Nr. 2, 2013. https://doi.org/10.1037/a0031311 
pag. 44

[18] Papert, S., Logo Philosophy and Implementation, 1999.

[19] Kafai, Y. B., Burke, Q., Constructionist Gaming: Understanding the Benefits of Making Games for Learning, Educational Psychologist, Vol. 50, Nr. 4, 2015. https://doi.org/10.1080/00461520.2015.1124022

[20] Papert, S., Solomon, C., "Twenty Things To Do With a Computer", Cambridge: Massachusetts Institute of Technology, 1971.

[21] Kazimoglu, C., "Empirical evidence that proves a serious game is an educationally effective tool for learning computer programming constructs at the computational thinking level", June 2013.

[22] Dan, S., "Robot Turtles" http://www.robotturtles.com/, 2013.

[23] Randolph, A., "Ricochet Robots", 1999.

[24] Leacock, M., "Pandemic" http://www.leacock.com/games/\#/pandemic/

[25] "Osmo Coding Family" https://www.playosmo.com/en/coding-family/

[26] McKinley Ross, S., "Qwirkle" http://www.ideaduck.com/qwirkle.htm

[27] Bauer, A., Butler, E., Popovic, Z., "Approaches for teaching computational thinking strategies in an educational game: A position paper". In Proceedings of the IEEE Blocks and Beyond Workshop 2015, pp. 121-123, 2015. https://doi.org/10.1109/BLOCKS.2015.7369019

[28] Apostolellis, P., Stewart, M., Frisina, C., Kafura, D., "RaBit EscAPE: A Board Game for Computational Thinking". In Proceedings Proceedings of the Conference on Interaction design and children - IDC 2014. https://doi.org/10.1145/2593968.2610489

[29] Fraser, N., "Ten things we've learned from Blockly". In Proceedings of the IEEE Blocks Beyond Workshop 2015. https://doi.org/10.1109/BLOCKS.2015.7369000

[30] Berland, M., Lee, V. R., Collaborative Strategic Board Games as a Site for Distributed Computational Thinking, International Journal of Game-Based Learning, Vol. 1, Nr. 2, 2011. https://doi.org/10.4018/ijgbl.2011040105

[31] Kazimoglu, C., Kiernan, M., Bacon, L., Mackinnon, L., A Serious Game for Developing Computational Thinking and Learning Introductory Computer Programming, Procedia - Social and Behavioral Sciences, Vol. 47, 2012.

[32] Tsarava, K., "Programming in Greek with Python", Aristotle Univerity of Thessaloniki, 2016.

[33] Echeverría, A., García-Campo, C., Nussbaum, M., Gil, F., Villalta, M., Améstica, M., Echeverría, S., A framework for the design and integration of collaborative classroom games, Computers and Education, Vol. 57, Nr. 2011. https://doi.org/10.1016/j.compedu.2010.12.010

[34] Barsalou, L. W., Grounded cognition, Annual review of psychology, Vol. 59, August 2008. https://doi.org/10.1146/annurev.psych.59.103006.093639

[35] Butz, M. V., Toward a unified sub-symbolic computational theory of cognition, Frontiers in Psychology, Vol. 7, June 2016. https://doi.org/10.3389/fpsyg.2016.00925

[36] Grover, S., Pea, R., "omputational Thinking in K-12: A Review of the State of the Field, Educational Researcher, Vol. 42, Nr. 1, 2013.

[37] Pea, R. D., Kurland, D. M., On the cognitive effects of learning computer programming, New Ideas in Psychology, Vol. 2, Nr. 2, 1984. https://doi.org/10.1016/0732-118X(84)90018-7

[38] Fullerton, T., Game Design Workshop: A Playcentric Approach to Creating Innovative Games, United Stated: Elsevier, 2008.

[39] Roungas, B., A Model-Driven Framework for Educational Game Design, The International Journal of Serious Games, Vol. 3, Nr. 3, July-September 2016.

[40] Poels, K., de Kort, Y. A. M., Ijsselsteijn, W. A., "D3.3: Game Experience Questionnaire: development of a self-report measure to assess the psychological impact of digital games", Eindhoven: Technische Universiteit Eindohoven, 2007.

[41] Curzon, P., McOwen, P. W., "The power of Computational Thinking", 1st ed. New Jersey: World Scientific, 2017. https://doi.org/10.1142/q0054

[42] Weintrop, D., Holbert, N., Horn, M. S., Wilensky, U., Computational Thinking in Constructionist Video Games, International Journal of Game-Based Learning, Vol. 6, Nr. 1, 2016. https://doi.org/10.4018/IJGBL.2016010101

[43] Shute, V. J., Kim, Y. J., "Formative and Stealth Assessment", Handbook of Research on Educational Communications and Technology: Fourth Edition, 2014. https://doi.org/10.1007/978-1-4614-3185-5_25

[44] Shute, V. J., Sun, C., Asbell-Clarke, J., Demystifying computational thinking, Educational Research Review, Vol. 22, September 2017. https://doi.org/10.1016/j.edurev.2017.09.003 